\title{
Antigenicity and Immunogenicity in HIV-1 Antibody-Based Vaccine Design
}

Leopold Kong ${ }^{1,2}$ and Quentin J Sattentau ${ }^{1 *}$

1 Sir William Dunn School of Pathology, University of Oxford, Oxford OX1 3RE, UK

${ }^{2}$ The Scripps Research Institute, 10550 North Torrey Pines Road, La Jolla, CA 92037, USA

\begin{abstract}
Neutralizing antibodies can protect from infection by immunodeficiency viruses. However, the induction by active vaccination of antibodies that can potently neutralize a broad range of circulating virus strains is a goal not yet achieved, despite more than 2 decades of research. Here we review progress made in the field, from early empirical studies to today's rational structure-based vaccine antigen design. We discuss the existence of broadly neutralizing antibodies, their implications for epitope discovery and recent progress made in antigen design. Finally, we consider the relationship between antigenicity and immunogenicity for B cell recognition and antibody production, a major hurdle for rational vaccine design to overcome.
\end{abstract}

\section{HIV-1 Vaccine Development and the Case for Inducing Neutralizing Antibodies}

Vaccines have allowed the control of many infectious human diseases, and eradication of one [1]. However, despite having identified the causative agent of AIDS as HIV-1 and characterized in large part its biological characteristics, we are still far from developing a prophylactic vaccine against this virus. The fact that HIV-1 infected individuals cannot clear the virus means that there is a lack of evidence from natural infection regarding immune correlates of protection [2]. The extraordinary mutation rate of HIV-1 arising from an error-prone polymerase (reverse transcriptase, RT) and the high propensity for recombination are major obstacles. When pitted against the immune system, such an adaptable virus readily diversifies into numerous variants that can escape the cytotoxic T cell (CTL) and neutralizing antibody (NAb) responses, fuelling ongoing infection [3,4]. The high degree of variability in the global viral population leads to two broad conceptual approaches to vaccine design: 1) To target only regions of high conservation in the viral antigens; 2 ) To target multiple regions of relative variability in a 'cocktail' approach. In the current review we will focus on the first of these concepts.

A question that presents itself in vaccine design is whether the vaccine needs to induce sterilizing immunity (preventing infection) or may allow infection but protect from disease. It seems likely that most successful vaccines protect from disease rather than infection, since adaptive immunity relies heavily upon antigenic restimulation to mount a secondary response, and the required levels of antigen can usually only be obtained after limited replication of the pathogen in the host. In the case of HIV-1, it may not be sufficient to rely upon vaccinemediated disease control post-infection, because once established in the host this virus is so extraordinarily able to evade the adaptive immune response. Although CTL are able to control HIV-1 replication in animal models of vaccination [5], their activation requires the infection of host cells, followed by recognition and killing. Thus unless CTL were able to clear all infected cells within a short period of time, fully aborting infection, it seems unlikely that true sterilizing immunity would be an outcome of this type of strategy. By contrast, Nab infused or actively elicited by immunization have provided complete sterilizing protection from experimental challenge in macaque models [2]. The same cannot be said of non-neutralizing $\mathrm{Ab}$, since their infusion fails to protect from challenge in macaque models [6,7], or results in weak, non-significant effects [8], or may even increase viral transmission across mucosal surfaces [9]. A major caveat of protection from challenge by active vaccination however, is that to date it has only elicited $\mathrm{Ab}$ that neutralize, and protect from, unusually neutralization sensitive viral strains [2]. The logical conclusion from these considerations is that Ab-mediated sterilizing immunity is a desirable feature of an HIV-1 vaccine, but that achieving this by active vaccination requires considerable further work.

A number of conventional vaccine development strategies have been implemented to combat HIV-1. They include the use of live-attenuated and inactivated viruses, and isolated viral envelope glycoprotein (Env)based subunit antigens. Whole inactivated vaccines have not shown much promise, and chemical inactivation processes may adversely modify Env, preventing or reducing NAb responses. An advantage of using a live-attenuated virus is that a broad range of immune responses is induced towards an entity that resembles the pathogen in almost every respect. However, the possibility of the attenuated virus reverting to pathogenicity is too significant a health issue [10]. In later studies more genes were deleted from SIV to further attenuate the virus, but this reduced vaccine efficacy and still failed to completely eliminate the risk of pathogenicity [11].

\section{The HIV-1 Envelope Glycoproteins as Vaccine Antigens}

HIV-1Envis the only target of NAb, and an Env-based subunit vaccine would, in principle, be safe and practical. Early experimental formulations in which the surface Env subunit gp120 was expressed in isolation showed that the antigen was safe and immunogenic in Phase I clinical trials [12]. Vaccinee sera, however failed to neutralize viruses other than the autologous, neutralization-sensitive isolate from which the gp120 sequence was derived [13]. This was explained by the observation that $\mathrm{Ab}$ in the sera from individuals vaccinated with gp120 mainly recognized linear epitopes within the hypervariable

${ }^{*}$ Corresponding author: Quentin J Sattentau, Sir William Dunn Schoo of Pathology, University of Oxford, Oxford OX1 3RE, UK, E-mail: Quentin.sattentau@path.ox.ac.uk

Received February 09, 2012; Accepted March 18, 2012; Published March 22 2012

Citation: Kong L, Sattentau QJ (2012) Antigenicity and Immunogenicity in HIV-1 Antibody-Based Vaccine Design. J AIDS Clinic Res S8:003. doi:10.4172/2155-6113. S8-003

Copyright: (c) 2012 Kong L, et al. This is an open-access article distributed under the terms of the Creative Commons Attribution License, which permits unrestricted use, distribution, and reproduction in any medium, provided the original author and source are credited. 
loops [14]. It was therefore no surprise that neither of the two HIV1 vaccine candidates based upon gp120 that completed Phase III efficacy trials protected vaccines [15-18]. In an effort to more closely recapitulate the antigenic structure of the intact viral spike, many laboratories then turned towards expression of trimeric antigens based upon gp120 linked to the extraviral portion of the transmembrane glycoprotein gp41, termed gp140. These trimeric gp140-based antigens can be expressed directly without modification, with site-directed mutations to stabilize structure or unmask conserved receptor binding regions, or as fusion proteins with a trimerization motif [19]. Some incremental improvements in Nab activity have been noted, and sterilizing immunity against challenge has been elicited in the macaque model [20], but overall the Nab response to these modified antigens is only incrementally improved in breadth and potency compared to that elicited by gp120 [19,21,22]. Reasons for this may include: i) trimeric Env is conformationally unstable and fluctuates between 'open' and 'closed' states [23]; ii) when cleaved at the gp120-gp41 interface, unmodified gp140 dissociates into its component subunits in a virus strain-specific manner [24-26]; iii)soluble Env conformation is not antigenically equivalent to the functional membrane-embedded Env trimer as probed by monoclonal antibodies (mAb) with epitopes sensitive to quaternary protein folding [27]; iv) when compared to whole virus or vectored delivery of viral genes, soluble subunit vaccine preparations lack both the abundant $\mathrm{T}$ helper cell epitopes from other viral proteins important for $\mathrm{T}$ cell help of $\mathrm{B}$ cell activation, and lack presentation in an array to optimally trigger the $\mathrm{B}$ cell receptor (BCR), and may therefore lack immunogenicity compared to their virionanchored counterparts [28].

This failure to elicit the appropriate quality and magnitude of $\mathrm{Ab}$ response has led to several questions. 1) Can HIV-1-infected individuals, and perhaps by extension Env vaccinated individuals, elicit $\mathrm{Nab}$ that bind highly conserved neutralization epitopes and thereby neutralize a broad range of viral variants (termed broadly neutralizing Ab or bNAb)? 2) If HIV-1 Env contains highly conserved neutralization epitopes such as the $\mathrm{CD} 4$ binding site (CD4bs), why are potent and broad-spectrum bNAb not elicited to those epitopes by active immunization? 3 ) What form of Env-based antigen might be designed to elicit bNAb?

\section{Conservation of Antigenic Surfaces on Env and Isolation of bNAbs}

The field has known for almost 2 decades that HIV-1-infected individuals can elaborate $\mathrm{NAb}$ responses to conserved neutralizing epitopes [2,29-31]. However, the frequency of these responses was unclear until a series of recent studies revealed that up to $25 \%$ of HIV-1-infected individuals may elicit bNAb responses [32-34]. Since overcoming the variation intrinsic to the circulating HIV-1 viral population will probably be the major challenge to eliciting NAb by vaccination, it is good news that such responses can be made relatively frequently in man. More recent optimism comes from the isolation of bNAbs from 'elite neutralizers' (HIV-1-infected individuals whose plasma neutralizes a broad range of viral isolates potently), that recognize, by definition, highly conserved structures on Env. Indeed, some bNAbs neutralize $70-90 \%$ of all circulating isolates [27,35-37], implying that their elicitation as individual or mixed specificities by vaccination might protect against the majority of circulating virus strains. The current 'crop' of bNAbs are summarized in [38] and those with structurally characterized epitopes in Figure 1. Existing bNAb epitopes fall into four broad regions: 1) the gp120 CD4bs; 2) a high mannose glycan patch on the outer domain of gp120 around the V3 loop area; 3) glycopeptide epitopes associated with the V1/V2 loops of gp120 that require quaternary Env interactions; 4) the Membrane Proximal External Region of gp41 (MPER) [38] (Figure 1). Others probably remain to be discovered, although the total number of conserved bNAb epitopes is predicted to be restricted [39,40], perhaps unsurprising given the very limited exposed protein surface area on Env. The isolation of bNAbs has direct relevance to vaccine design. Co-crystallization of the bNAb with its epitope yields information regarding which exposed conserved regions on the antigen can elicit an $\mathrm{Ab}$ response, and the epitope structure may help guide subsequent vaccine antigen design [41-44].

\section{HIV-1 Neutralizing Antibody Evasion Mechanisms}

Throughout the history of developing aNAb-based vaccine against HIV-1, a pressing question has emerged but remains largely unanswered: how can the biophysical properties of the antigen be translated to specific kinds of immune responses in a highly defined manner? What is clear from the work carried out previously using Env-based immunogens, is that the presence of an epitope on the antigen is no guarantee that that epitope will be recognised by $\mathrm{B}$ cells and responded to by $\mathrm{Ab}$ production. This invokes the concept of $\mathrm{B}$ cell immunodominance in antigen recognition. A definition of humoral immunogenicity is the capacity of an antigen to elicit $\mathrm{Ab}$. Certain portions of the antigen may elicit more $\mathrm{Ab}$ than others and thus be more immunogenic, and this is termed immunodominance. B cell immunodominance may be defined experimentally by defining those surfaces of an antigen that elicit the greatest number and titre of antibody responses to those that elicit reduced or absent responses, or theoretically by modelling specific biophysical parameters of the antigen surface in question. $\mathrm{B}$ cell immunodominance is much less well understood than $\mathrm{T}$ cell immunodominance [45], but is substantially dictated in the case of HIV-1 Env by viral NAb evasion strategies which can be summarised as follows. 1) Use of extensive sequence variation [46,47]. 2) Presence of the glycan shield, which is largely immunogenically invisible to the host immune system, to mask protein surface from Ab binding [48-51]. 3) Use of conformational masking to avoid or reduce B cell recognition and $\mathrm{Ab}$ binding [52,53]. 4) Presence of non-functional, misfolded and precursor Env, gp41 'stumps' and shed monomeric gp120 as decoys for B cell recognition [54,55].5) Recessed or cryptic receptor and co-receptor binding sites [56-58]. If this evidence is taken together, it becomes clear that HIV-1 Env is an extraordinarily evolved machine that combines function (receptor binding and membrane fusion) with multiple layers of immune evasion. Probably the most difficult problems to overcome are the phenomenal level of sequence variability in Env combined with the very limited protein surface exposed on the intact trimeric spike. The most direct way to overcome this is to target precisely those conserved exposed regions as defined by bNMAb probes: the existence of such bNMAbs provides proof of principle for the existence of such conserved surfaces, and leads directly to structural analysis of these surfaces to guide subsequent antigen design.

\section{Epitope Mimicry and Structure-Based Antigen Design}

Structure-based vaccine design posits that if one has the structure of an $\mathrm{Ab}$ epitope, then that epitope can be engineered to be presented in a different context, and used to elicit the original $\mathrm{Ab}$ specificity by immunization [41,42] and Figure 2. This is an attractive concept, since our ability to generate a specific bNAb epitope could in theory lead to elicitation of large amounts of the corresponding bNAb specificity in vivo. The recent use of molecular 'scaffolds', small structurally-defined domains obtained from the protein data base that constrain and present conformationally-sensitive epitopes in a manner that precisely mimics 
Citation: Kong L, Sattentau QJ (2012)Antigenicity and Immunogenicity in HIV-1 Antibody-Based Vaccine Design. JAIDS Clinic Res S8:003. doi:10.4172/21556113.S8-003

that on the intact antigen, has been a major advance in structure-based vaccine design $[59,60]$. However, whilst proof-of-principle evidence exists for the precise engineering of specific bNAb epitopes that are structurally almost identical to their native counterparts, their use as immunogens has generally been less fruitful. Early encouraging data were obtained using synthetic peptide epitope mimics of the gp120 V3 loop, in accord with its immunodominant nature [61-63] and coreceptor binding function [61]. The more successful variants of this target have been based upon selection of constrained epitopes using $\mathrm{Ab}$ binding [64] or epitope structure-based design [65]. However, it is well recognized that the V3 loop is usually only exposed to Ab binding on functional Env of unusually neutralization sensitive viruses [63], limiting the usefulness of this approach, although this view is challenged by some [66]. Nevertheless, the use of epitope mimics of the V3 loop provide direct proof-of-principle that such minimal engineered constructs can induce a NAb response against HIV-1.

The concept of generating a single specificity or a very limited set of related specificities of MAb from immunization with an epitope mimic differs from conventional vaccine approaches that rely upon polyvalent responses to complex antigens $[67,68]$. It has been suggested that structure-based vaccine design is fundamentally flawed, since the continuous and unpredictable nature of $\mathrm{Ab}$ epitopes on an antigen make reiteration of a particular Ab specificity by an isolated epitope mimic highly improbable[67-69].However, the outcome of the epitope mimic approach is likely to depend to great extent upon the intrinsic immunogenicity of the epitope in question, since as described above, isolated fragments of the gp120 V3 loop are able to induce robust oligoclonal $\mathrm{Ab}$ responses that are neutralizing for a subset of HIV1 strains. This result contrasts with the failure, to date, of engineered epitope mimics of the MPER region of gp41 to elicit the desired specificity of HIV-1 Nab, although this failure has specific caveats relating to lipid recognition (see below and [59,70-72]). Thus a major question stemming from this debate is whether the immunogenicity of particular epitope or epitope mimic is entirely pre-determined by its intrinsic immunodominance, or whether the immunodominance of an epitope is relative and can be modulated experimentally. This question is discussed further in later sections.

\section{MPER Epitope Mimics}

The MPER peptide epitopes for bNMAbs 2F5 and 4E10 (Figure 1)

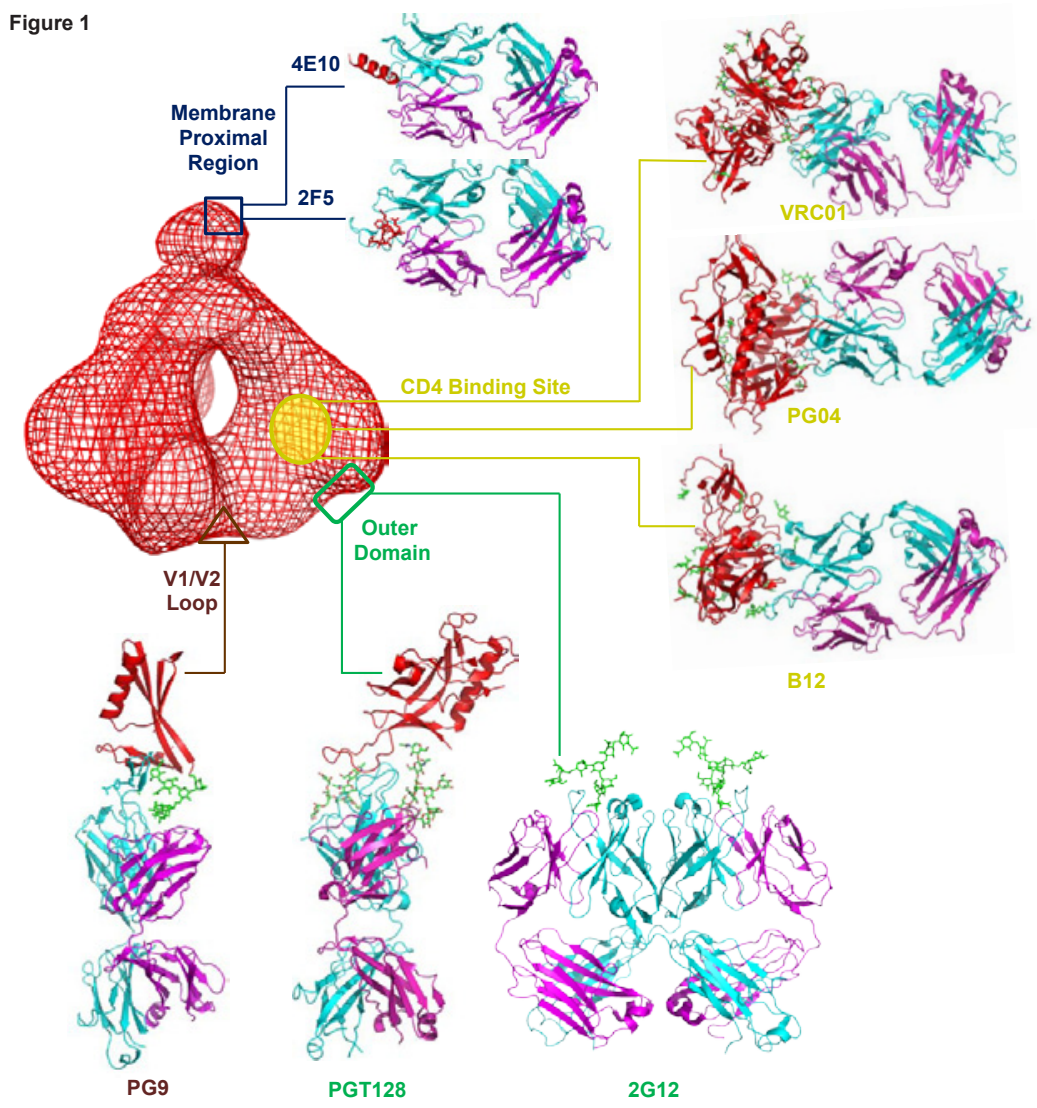

Figure 1: The epitopes of four classes of bNMAb.

Currently, there are four broad classes of bNMAb against the HIV-1 trimeric spike (red): Ab that bind the membrane proximal region (blue), the CD4bs (yellow), the oligomannose patch on the outer domain with or without implication of the V3 loop (green) and the V1/V2 domain (brown). Representatives of each class have been extensively structurally characterised. Here, these are shown alongside a low-resolution cryo-EM map of the unliganded gp160 spike (EMDID: 5019 ) (red mesh) oriented with the viral membrane on the top. In the gp41 portion, the two bNMAb that recognize the membrane proximal region are shown: 4E10 (PDBID: 2FX7) and 2F5 (PDBID:1TJG). Beneath that, in the gp120 portion, are bNMAb that recognize the CD4bs: VRC01 (PDBID: 3NGB), PG04 (PDBID: 3SE9) and b12 (PDBID: 2NY7). Also in the gp120 portion are bNMAb that bind the outer domain region around the V3 loop: 2 G12 (PDBID: 1 OP5) and PGT128 (PDBID: 3TYG). Finally at the bottom is a bNMAb that binds a quaternary-fold-dependent epitope in the V1/V2 domain: PG9 (PDBID 3U2S). Here, all structures are displayed in cartoon format with the heavy chains of the Ab coloured cyan, the light chains coloured magenta, the gp120 protein portions coloured red and the gp120 glycan portions coloured green. 
are structurally defined $[73,74]$, and have been mimicked in a number of laboratories by synthetic peptides that bound the bNM Abs with relatively high affinity. However, although capable of eliciting specific $\mathrm{Ab}$ responses to the peptide [30,70,71,75-81], MPER epitope mimetics have so far failed to elicit appropriately strong bNAb responses. This is despite recent results showing that scaffolded peptide epitope mimics induced an $\mathrm{Ab}$ response in mice that bound an epitope conformation almost identical to that bound by the starting bNAb, 2F5 [70]. The conclusions reached after a decade of intensive research are that conformation and appropriate lipid presentation of the epitope mimic are critical to eliciting Abs of the desired specificity [70,82] (Table 1). Thus the $2 \mathrm{~F} 5$ epitope probably requires precise insertion into a lipid interface, thereby presenting the epitope in a manner allowing appropriate 'extraction' from the membrane [82]. Moreover, the steric

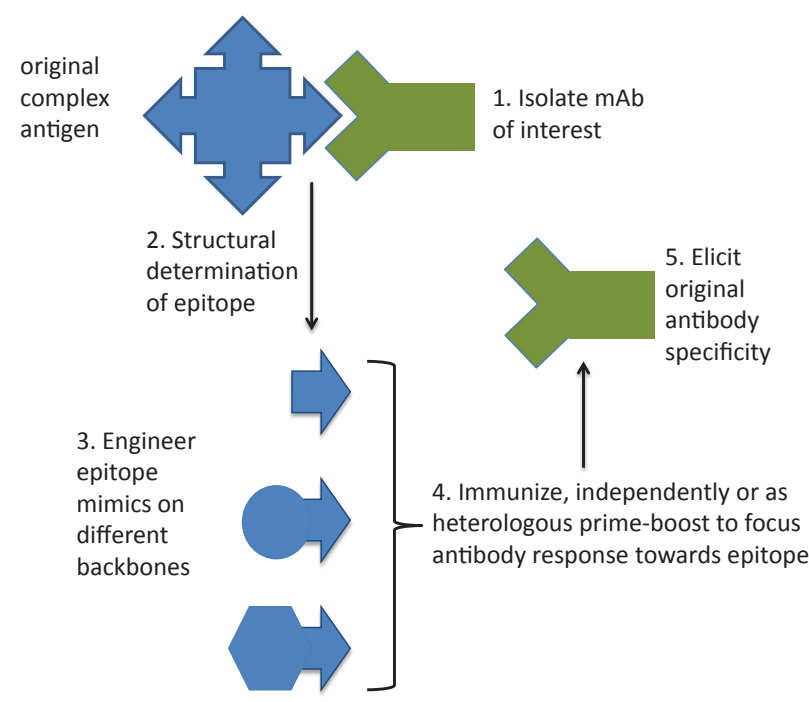

Figure 2: The structure-based vaccine antigen design strategy

The flow of steps in the process is shown here. The original complex antigen or a subcomponent of it is co-crystallized with a bNMAb to reveal atomic-level structural information about the epitope. The epitope is then recapitulated as a constrained mimic using scaffolds as backbones to present the epitope. If several different backbones are generated that present essentially the same epitopic structure, then these can be used in a series of heterologous immunizations to selectively amplify $B$ cell responses to the epitope. If the strategy works, then the outcome would be the generation of a polyclonal B cell response containing bNMAb specificities that resemble the original template bNMAb. effects of having the MPER peptide epitope 'sandwiched' between the glycans of the Env trimer and the lipid envelope may make direct $\mathrm{Ab}$ association with the lipid bilayer a requirement, in order to achieve the appropriate angle of approach to the peptide epitope $[43,44,70]$. These studies reveal that protein engineering has reached a level of sophistication whereby peptide mimics of conformational epitopes can be constructed with high fidelity, and can elicit $\mathrm{Ab}$ responses of appropriate peptide specificity. However they also demonstrate that we have yet to successfully combine recognition of peptide surfaces with concurrent recognition of other antigenic structures such as lipids and glycans (Table 1) to yield composite bNMAb epitopes such as those presented in the gp41 MPER. Finally, a further level of complexity is introduced by the fact that lipid association promotes an elevated level of autoreactivity with cell membranes and other host cell components, implying that self-tolerance mechanisms may need to be overcome to generate such $\mathrm{Ab}$ responses [83-85].

\section{Mimics of Epitopes Dependent Upon Tertiary and Quaternary Env structure}

Much recent effort has gone into designing polypeptide mimics of discontinuous epitopes, with the gp120 CD4bs being most relevant to current HIV-1 vaccine design. This surface is, by definition as a contact surface for a non-polymorphic receptor, relatively highly conserved, although it is flanked by, and contains, islands of variability and conformational flexibility [86]. A sub-component of the CD4bs, however, is highly conserved and conformationally stable, and has been termed a 'site of vulnerability' [87]. This region contains epitopes for very potent and broad NMAb such as VRC01 [36,88]. Early attempts to isolate epitope mimics used phage expression libraries linked with binding to the only available bNMAb, IgG1b12 (b12), for selection. Although peptide mimics were isolated, the affinity of b12 for the resulting mimics, where tested, was still substantially below that of the affinity for the native gp120 [89-92]. It was therefore not surprising when immunization studies with these polypeptides failed to elicit robust b12-like responses or detectable neutralization. A more sophisticated approach has recently been adopted that relies upon reiterating the b12 epitope molecular surface by constraining a polypeptide into the correct conformation using a designed molecular scaffold [93]. The scaffold was created by selecting molecules from the protein structural database that had the appropriate 'fit' for constraining the b12 mimic into the correct fold, then the mimic was reiteratively modeled and mutated within the epitope and backbone until binding affinity for b12 attained that of the native antigen $(\sim 10 \mathrm{nM})$. Structural analysis revealed a strong similarity between binding of b12 to the

\begin{tabular}{|c|c|c|c|c|c|}
\hline Antibody & Epitope region & Epitope type & Structure known? & Hurdles to overcome & Key references \\
\hline $2 \mathrm{~F} 5,4 \mathrm{E} 10$ & gp41MPER & $\begin{array}{l}\text { Continuous, conformational } \\
\text { and composite (protein-lipid) }\end{array}$ & $\begin{array}{l}\text { Yes, but only in context of } \\
\text { antibody-peptide complex }\end{array}$ & $\begin{array}{l}\text { Instructing B cells to recognize peptide- } \\
\text { lipid antigens. Overcoming immune } \\
\text { tolerance mechanisms without inducing } \\
\text { autoimmune pathology }\end{array}$ & {$[70,71,73,74,82]$} \\
\hline $\begin{array}{l}\text { b12 } \\
\text { VRC01 }\end{array}$ & gp120CD4bs & Discontinuous protein & $\begin{array}{l}\text { Yes, in context of core gp120 } \\
\text { and also at lower resolution with } \\
\text { cryo-EM in context of trimer }\end{array}$ & $\begin{array}{l}\text { Focusing B cell responses towards 'site } \\
\text { of vulnerability', overcoming low immu- } \\
\text { nogenicity, instructing antibody 'angle of } \\
\text { approach' to trimer }\end{array}$ & $\begin{array}{l}{[37,38,86,87,88,93,112,} \\
114,127]\end{array}$ \\
\hline PG9, PG16 & gp120 quaternary V1/V2 & $\begin{array}{l}\text { Continuous, conformational, } \\
\text { composite (protein-glycan) }\end{array}$ & $\begin{array}{l}\text { Yes in context of constrained } \\
\text { mimetic }\end{array}$ & $\begin{array}{l}\text { Instructing B cells to recognize glycopep- } \\
\text { tide epitopes }\end{array}$ & [95] \\
\hline PGT 128 & Gp120 glycopeptideV3 & $\begin{array}{l}\text { Continuous, conformational, } \\
\text { composite (protein-glycan) }\end{array}$ & $\begin{array}{l}\text { Yes in context of outer domain } \\
\text { construct of gp120 }\end{array}$ & $\begin{array}{l}\text { Instructing B cells to recognize glycopep- } \\
\text { tide epitopes }\end{array}$ & {$[97]$} \\
\hline $2 \mathrm{G} 12$ & gp120 glycan & Discontinuous glycan & $\begin{array}{l}\text { Yes in context of synthetic } \\
\text { glycans }\end{array}$ & $\begin{array}{l}\text { Instructing B cells to recognize glycans. } \\
\text { Presenting glycan arrays that appear } \\
\text { foreign to host and may not require } \\
\text { breaking of immune self tolerance }\end{array}$ & [101] \\
\hline
\end{tabular}

Table 1: A summary of bNMAb families with their epitope type, structure and major hurdles to overcome to develop an antigen capable of eliciting bNMAb. 


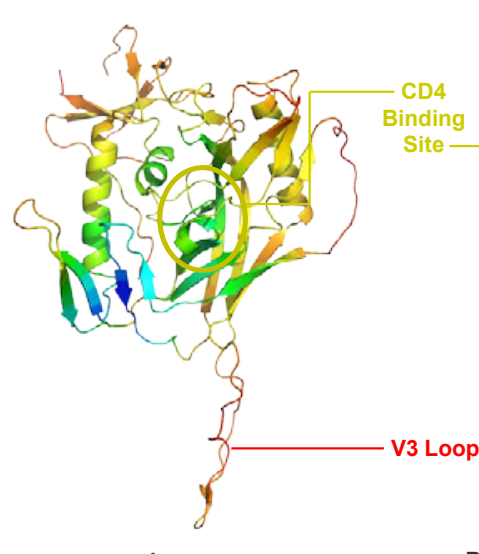

B-value $\left(\AA^{2}\right): 52.3$ - 153.4

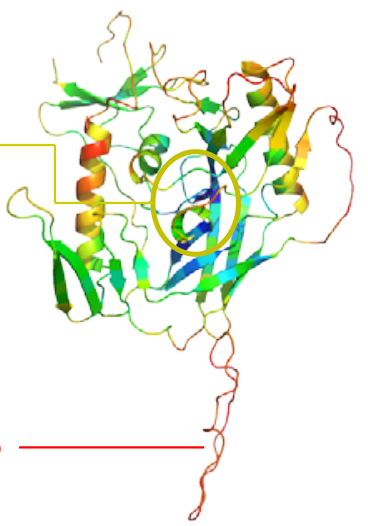

B-Cell Immunogenicity: $-1.0-2.0$ recessive

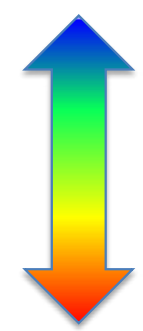

dominant

Figure 3: HIV-1 gp120 flexibility and predicted B-cell immunogenicity.

Here the structure of gp120 containing an intact V3 loop (PDBID: 2B4C) is shown in cartoon representations coloured by heat gradient $($ blue $=$ least, red $=$ most), according to either its crystallographic b-value -a measure of flexibility (left), or to its predicted b-cell immunogenicity by the BEprot server (right). The two representations are oriented to fully display the CD4bs, which has been circled in yellow.

mimic and to native gp120 [93]. Moreover, this scaffolded epitope was selectively unable to bind another weakly neutralizing CD4bs MAb b13, implying strong specificity for b12. This is an impressive engineering achievement that sets the scene for development of further mimics of complex discontinuous epitopes.

Other recent studies have generated interest in bNMAbs that bind epitopes requiring conservation of the quaternary fold of Env. The prototype for this family is the $2909 \mathrm{mAb}$ that binds an epitope dependent upon residues within the gp120 V2 and V3 regions [94]. Whilst this MAb is exceptionally potent, it is highly virus strain-specific. By contrast, the clonally-related bNMAbs PG9 and PG16 neutralize $70-80 \%$ of viral strains tested with high potency [27]. Their epitopes are dependent upon maintenance of Env folding, to the extent that no soluble glycoprotein, even when trimerized, maintains the epitope in its native, high affinity conformation [27]. The epitope of PG9 is contained within a region of the V1/V2 domain, and has been recapitulated using a scaffolded glycopeptide mimetic [95]. Within the epitope the PG9 paratope contacts a single $\beta$-strand and two flanking glycans that form a mini-canyon structure $[95,96]$. The independent solution of the structure of another bNMAb of different specificity, PGT 128 that binds an epitope in the gp120 V3 loop, reveals fascinating insight into convergence of molecular recognition. Both PG9 and PGT 128 bind a similar glycopeptide-canyon structure using related structural solutions [95-97]. This convergence suggests that the limited area of conserved protein surface on HIV-1 Env has selected B cell clones that can penetrate the glycan shield and bind conserved peptide sequences that would otherwise be masked by the glycans. Such recognition appears to require an unusually long CDR H3 loop and a high degree of affinity maturation, potentially making active elicitation of this type of $\mathrm{Ab}$ difficult (Table 1). However this is now experimentally testable using the epitope mimics made for co-crystallisation purposes, or structurally related antigens, as immunogens.

\section{Glycan-based Mimics}

HIV-1 Env is heavily glycosylated, which helps HIV-1 evade Ab recognition but also reduces the accessibility of its receptor binding sites $[48,50]$. These opposing selective pressures restrict the number of glycans to $15-32[48,49]$. When further packed into a trimer, gp120 glycans are so crowded that their enzymatic processing may be inhibited, affecting the type of glycans produced [98]. Such tight clustering of glycans allows for $\mathrm{Ab}$ recognition, since high density packing of this sort is absent in the host even though the individual glycans are hostderived $[35,95,97,99]$. The 2 G12 bNMAb (Figure 1) binds to such a tight cluster of oligomannose glycans on the outer domain of gp120 [99-101], giving an example of the immune system taking offensive action against this viral defence. Speculation [102] that synthetic glycan epitopes might elicit $\mathrm{Ab}$ responses specific for those antigens has been rewarded $[103,104]$, although the resulting Abs did not significantly cross-react with gp120. Modification of yeast polysaccharide biosynthesis created an immunogen that did induce gp120-reactive Abs, but these were only very modestly neutralizing [105]. Future approaches may need to recreate more precisely the orientation and presentation of the glycans to achieve higher affinity binding leading to increased neutralization activity. In this regard the recent isolation of several new glycan binding bNMAbs is of particular interest [35].

\section{Understanding B Cell Immunodominance}

Structure-based rational vaccine design proposes that direct and intentional modifications to the biophysical profile of an antigen can result in the controlled focusing of the humoral immune response to any selected antigenic surface $[41,59,106]$. However, this hypothesis relies entirely on the assumption that one or more B cell clones cells will recognise any antigenic fragment presented to them and respond by producing $\mathrm{Ab}$ identical to, or similar to, those used as a template to design the antigen. This concept makes assumptions about B cell immunodominance that may be naive. Whereas the biophysical profile of antigen-Ab interaction is strictly chemical and highly quantitative, the immune response consists of several interdependent biological processes that can only be qualitatively described. These processes involve both intrinsic and extrinsic factors including, but not limited to, the fate of antigen in vivo, the use of adjuvants, VDJ region recombination, $\mathrm{T}$ cell help, affinity maturation and self-tolerance $[68,107]$. Despite this complexity, the effects of certain biophysical properties of the antigen on the $\mathrm{Ab}$ response are partially understood and will be discussed here.

Immunodominance may be experimentally determined by 
mapping serum activity through binding competition assays using a panel of $\mathrm{mAb}$ with well defined epitopes, and by measurement of $B$ cell clonal frequency to specific epitopes by production of $\mathrm{mAbs}$ or $\mathrm{Ab}$ sequences. Additionally, since there are clear biochemical determinants of protein binding such as surface accessibility and hydrophilicity, it may be possible for $\mathrm{Ab}$ binding propensity to be modelled and subjected to computational prediction. Here we used used COBEpro [108], a discontinuous B-cell epitope prediction software that takes into account accessibility and side chain orientation, to predict the $\mathrm{Ab}$ binding propensity of a gp120 construct with intact V3 loop (Figure 3). The computational prediction shows that it is most likely for Ab to bind the V3 loop along with some other well-exposed portions such as the V4 loop and the inner domain. Interestingly, V3 loop immunodominance is what one would predict from previously published empirical results $[14,61]$. The algorithm gives high scores to those regions of the protein that appear to be more accessible, an expected result as there would be more ways for different BCR to bind a region when it is more exposed. The CD4bs is strikingly immunorecessive, no doubt as a partial consequence of being a shallow recessed canyon [86]. Another parameter used for predicting $\mathrm{Ab}$ binding propensity is flexibility $[109,110]$. If applied to gp120, it would also select the flexible hyper variable loops as being the most immunogenic. Indeed when a measure of flexibility, the b-value of gp120 is directly compared to the BEprot prediction, the resulting pictures are remarkably similar with high $b$-value regions matching high BEprot predicted B-cell immunodominance (Figure 3). Some supporting experimental evidence comes from a recent effort to elicit $\mathrm{Ab}$ against a transplanted epitope of gp41. The immunogenicity of the epitope graft correlated significantly with its flexibility [70]. In this case, greater flexibility may mean greater number of adopted shapes for $B C R$ recognition, allowing a greater variety of $B$ cell clones to bind and become activated.

A third parameter is BCR affinity for antigen since that is an important factor for B-cell survival within the germinal centre during affinity maturation. A detectable B-cell response requires at least micromolar affinity of BCR for antigen [111]. Optimizing this affinity would mean being able to measure binding of the antigen to the highly variable germ line receptors in every patient, which may be possible through personalized deep sequencing followed by variable region expression [112]. However, modification of an antigenic surface to promote BCR binding may well introduce novel ways of binding it that may not be present in the original antigen. This type of directed BCR evolution would result in the maturation of $\mathrm{B}$ cells whose receptors ultimately may not recognize the original antigen.

\section{Epitope Focussing and Other Strategies to Modify B Cell Immunodominance}

Focussing B cell responses away from immunodominant regions of an antigen towards subdominant (immunorecessive) regions is an attractive concept that deserves further investigation. However, its success is based upon the concept that immunodominance is relative, so that removal of an immunodominant segment will increase the immunogenicity of a previously more immunorecessive segment. This would suggest some form of competition in immunogenicity, as has been described for $\mathrm{T}$ cell epitopes [113], but for which there is not yet compelling supportive evidence for B cells. Conversely, if immunodominance is absolute, based solely on the constraints imposed by biophysical recognition of a surface by a given BCR, then there is no reason to suppose that such a strategy will work. However, as discussed above, $\mathrm{Ab}$ responses are not governed by biophysical parameters alone. The immunodominance of a surface may be influenced by biological factors such as the local frequency of B cells carrying appropriate BCRs, availability of $\mathrm{T}$ cell help and masking of epitopes by pre-existing $\mathrm{Ab}$ and/or receptor binding (as in the case of CD4-gp120 binding).

\section{Env trimers and modified trimers}

Considering these parameters, it is possible to formulate and test various hypotheses regarding the directed modification of immunogenicity. A common hypothesis is that maximizing the accessibility to Env surfaces recognized by bNAbs while minimizing accessibility to surfaces recognized by non-NAbs would result in a focused immune response to those surfaces recognized by bNabs $[87,114]$. One way to modify accessibility is to use Env in its native trimeric fold as found on the virion surface. It has long been observed that $\mathrm{Ab}$ neutralization correlated with binding to trimer instead of gp120 monomer [115-117]. Moreover, trimer-stabilizing motifs such as GCN4 fused to gp140 elicited sera that better neutralized homologous and heterologous primary HIV-1 isolates than monomeric gp120elicited sera [118]. Superior immunogenicity was also observed for gp140 trimers stabilized by intramolecular disulphide bonds relative to monomeric gp120 [22], possibly as a result of increased BRC crosslinking and B cell activation. The recent discovery of Nabs with broad activity that are trimer specific also encourages its use $[27,95,119,120]$. However, the trimer in situ on the virion surface is relatively labile, shedding gp120 in a virus strain-dependent manner [53,121-123]. This problem is exacerbated when the trimer is solubilized by expression in a truncated soluble form without transmembrane anchor. Use of trimerization motifs may help stabilize the trimer, but the resulting oligomer may not represent the functional spike on the virus [124,125], as for example determined by binding of quaternary epitope-specific bNMAb [27]. This leads to the more general problem of defining the structure of a proper trimer mimic of the functional spike. Indeed, most spikes on a virion are defective $[48,54]$ and so the only defining indication for proper oligomerization is functionality in viral entry. Also, like the flexible gp120 monomer [126], the trimer may sample many quaternary conformations, making the idea of a single proper trimer untenable. Cross-linking of the trimer to stabilize it into its different conformers followed by selection of appropriate trimer forms using bNABs such as PG9 is a potential strategy. Low resolution $(\sim 20 \AA)$ cryo-electron tomograms of the trimer offer useful information on how it is organized [127]. However, these densities will average data from all spikes, both functional and defective; parameters for selection of only functional spikes would be difficult to define. If testing the hypothesis requires a pure preparation of the functional Env, either in membrane anchored or soluble form, then it appears much further work on the trimer structure will be necessary.

\section{Eliminating or modifying unwanted antigenic regions}

Another way to modify epitope accessibility is to excise portions of the protein that influence the immunodominance and surface exposure of the overall protein. For example, macaque sera against V2 loop (which partially masks the CD4bs) -truncated gp140 trimers showed increased breadth of neutralization activity [128]. A more extreme excision removed the entire inner domain of gp120, resulting in stable outer domain only constructs [129-131]. Mouse immunization with a clade $\mathrm{C}$ outer domain containing an intact V3 loop resulted in predominantly $\mathrm{V} 3$ specific $\mathrm{Ab}$ responses [131], testifying again to the immunodominance of this loop. Moreover, although not assayed for in this study, excision introduces new surfaces at the cutting zones as well as altered surfaces around the regions that were cut, creating neoepitopes. Distal structural effects as a result of conformational changes 
are also possible. Such neo-epitopes may be more immunodominant than the regions of interest. Empirical studies with further modified outer domain constructs will be required to test this approach.

Another approach was based upon creating a chimeric antigen that contained elements of the CD4bs within a 'resurfaced', or antigenically modified, molecular context [36]. To achieve this, the gp120 'core' antigen from HIV-1, lacking the V1/V2 and V3 loops, was substituted in regions surrounding the CD4bs with amino acids from the homologous simian immunodeficiency virus (SIV) molecule, which is structurally related to HIV-1 gp120 but differs substantially at the amino acid level. In this way the HIV-1 CD4bs was conserved within an antigenically distinct SIV context. Additional glycan sequons were added to neutralization-irrelevant surfaces to exclude irrelevant $\mathrm{B}$ cell recognition. Use of this construct allowed the isolation of the highly potent and broadly reactive CD4bsmAb VRC01 and its bNMAb relatives from an HIV-1-infected patient, highlighting its focused antigenicity for the HIV-1 CD4bs [36]. Immunogenicity studies with this type of construct are underway.

\section{Glycan masking and unmasking}

A related strategy for focusing $\mathrm{Ab}$ responses towards a specific epitope or epitope region relates to maintaining the surface of interest within the native composite antigen whilst physically masking regions irrelevant to induction of bNAb. Approaches to this involve incorporation of additional N-linked glycosylation sequons on surfaces and loops of Env [132-134]. Application of this masking strategy was by engineering multiple $\mathrm{N}$-linked glycan sequons into the gp 120 coding sequence that were modeled to occlude protein surfaces apart from theCD4bs [135]. The optimization and expression of these constructs resulted in a higher level of gp 120 glycosylation, an antigenic profile that reflected selective masking of neutralization-irrelevant gp120 surfaces, and optimal exposure of the b12 epitope $[133,135,136]$. However immunogenicity of the hyperglycosylated antigens was globally reduced in vivo, and did not reflect their antigenicity in that no detectable b12like responses were elicited $[133,137]$. Mutations required to introduce the new glycans decreased protein expression levels and therefore must have had a negative impact on folding efficiency. While some of the protein stabilizing effects of glycans are known, especially on the peptide backbone, the overall conformational effect of excising or adding glycans is unpredictable [138-140]. In order to avoid destabilizing effects, statistical analysis of the protein environment around glycans can be used as a guide to select the best sites for modification [141]. Only those environments in which glycosylation is most likely to be observed should be targeted. For example, turns and random coils are preferred over helices, and certain shapes such as small pockets or convex hills appear to be better for glycosylation. Ultimately, common biochemical rules such as not perturbing protein core packing or disrupting salt bridges would also apply.

An opposite approach has been to remove or modify glycans on gp120 to better expose neutralizing epitopes [142,143]. Deletion of glycans can sensitize viruses to neutralization by both CD4bs and CD4i Ab. Ultimately; however, it is unknown whether elimination of glycans adds neo-epitopes that skew the $\mathrm{Ab}$ response away from $\mathrm{nAb}$ induction. Moreover, $\mathrm{Ab}$ affinity to gp 120 epitopes can be drastically altered by the presence of glycans that are very distant from them, suggesting a largely unpredictable reshuffling of the entire glycan shield whenever any glycan is modified $[48,133]$. This shifting of the glycans might be better understood given increased understanding of biophysical parameters gleaned from structures. However, with the exception of the unliganded SIV gp120 [144], structures of gp120 with full glycans remain elusive.
Furthermore, the glycan shield can be properly understood only in the context of the trimer, in which the majority of solvent exposed protein surface would be occluded. As with previously described methods of altering accessibility, progress in testing the glycan approach would require much empirical experimentation with different glycan modifications as well as use of structural information as a guide for designing the modifications. A more subtle approach adopted recently is to reduce glycan complexity to maintain the total number of glycans present, but decrease their steric encumbrance. Production of gp120 in insect cells or mammalian cells treated with Kifunensine [145], or grown in mammalian cells lacking $\mathrm{N}$-acetylglucosaminetransferase I (GnTI) [146], resulted in glycoproteins carrying oligomannose 'stumps' lacking sialic acid termination. This led to increased exposure of the CD4bs in both studies, which encouragingly translated to increased CD4bs immunogenicity [145].

\section{Molecular Mimicry and The Case of Anti-Idiotypes}

In the early days of HIV vaccine design, the anti-idiotype hypothesis was invoked as a possible method of generating NAb responses by using $\mathrm{Ab}$ as antigens. The concept was based around the idea that an $\mathrm{Ab}$ recognising an antigen could itself be used as an antigen for immunisation, and secondary Ab raised against the first Ab's paratope would then recognise the antigen. Looking back this seems naive, as making a 'carbon copy' of a complex three-dimensional surface that could then be used to generate an exact mirror image in vivo seems extremely unlikely to take place at any detectable frequency. Indeed, this was the outcome of the empirical analysis, since several laboratories carried out multiple immunisations in mice but failed to obtain convincing proof-of-principle for the concept [147]. A later analysis of molecular mimicry undermined the entire concept of using anti-idiotype networks as a strategy with any practical utility [148], after which it was abandoned for HIV vaccine purposes. The anti-idiotype approach is not directly comparable to current rational vaccine design, not least because of the wealth of detailed structural information available to guide current attempts. Nevertheless, the idiotype story provides a cautionary backdrop to the idea that antigenicity can be predictably converted to immunogenicity.

\section{Conclusion}

Phenomenal progress has been made in the past few years regarding our understanding of the structure of bNMAb epitopes on HIV-1 Env. Sophisticated epitope mimics have been engineered that are excellent structural look a likes of the starting epitope within the native antigen. The major challenge now is to determine whether an $\mathrm{Ab}$ response to such mimics can be elicited that recapitulates the starting bNMAb in specificity and affinity (Table 1). We already know from previous studies with complex antigens such as $\mathrm{AbV}$ regions (anti-idiotype strategy) that eliciting $\mathrm{Ab}$ to specific protein epitopes can be very difficult. The biological hurdles implicit in 'training' B cells to recognize composite epitopes comprised of protein-glycan or protein-lipid are unknown, but the apparent rarity of such specificities probably testifies to the complex B cell evolution required to elicit them. One strategy that has yet to be tested is a form of instructive evolution of B cells in which one 'teaches' the B cell to see each component of a complex protein or composite epitope one step at a time, from germ line BCR to plasma cell secreting high affinity $\mathrm{Ab}$. Having access to phylogenetically dissected bNAb lineages may help illuminate a path along which B cells could be matured towards a particular antigenic endpoint [112].

It has been proposed that rational vaccine antigen design may represent an elevation of vaccine research from an empirical exercise to 
a scientific discipline [58]. Others have argued that the structure-based vaccine design concept is set in opposition to empirical studies $[67,68]$. However, as the current literature clearly attests, rational vaccine design it is not a purely theoretical exercise devoid of experimental trial-and-error investigation. Optimization of antigens for $\mathrm{Ab}$ binding, with possible optimization of a series of antigens for iterative BCR activation, heterologous prime and boost regimens to focus responses towards conserved regions and use of diverse immunization schedules and adjuvants can all be exhaustively tested by experiment. Rational vaccine design was born from the frustration arising from the failure of conventional strategies and, as described above, challenges the basic quantitative/qualitative divide that separates the chemical description of an antigen and its biological effect on immunity. It is a hypothesis that invites much empirical testing, and while its ultimate practical goal may be an effective vaccine for HIV-1, its study will undoubtedly deepen our understanding of immunology in a reductionist manner that goes along with the general spirit of synthetic biology that has taken hold of contemporary research.

\section{References}

1. Plotkin SA (2009) Vaccines: the fourth century. Clin Vaccine Immunol 16: 17091719.

2. Mascola JR, Montefiori DC (2010) The role of antibodies in HIV vaccines. Annu Rev Immunol 28: 413-444.

3. Korber B, Gaschen B, Yusim K, Thakallapally R, Kesmir C, et al. (2001) Evolutionary and immunological implications of contemporary HIV-1 variation. Br Med Bull 58: 19-42.

4. Zhuang J, Jetzt AE, Sun G, Yu H, Klarmann G, et al. (2002) Human immunodeficiency virus type 1 recombination: rate, fidelity, and putative hot spots. J Virol 76: 11273-11282.

5. Koup RA, Douek DC (2011) Vaccine design for CD8 T lymphocyte responses. Cold Spring Harb Perspect Med 1: a007252.

6. Shibata R, Igarashi T, Haigwood N, Buckler-White A, Ogert R, et al. (1999) Neutralizing antibody directed against the HIV-1 envelope glycoprotein can completely block HIV-1/SIV chimeric virus infections of macaque monkeys. Nat Med 5: 204-210.

7. Mascola JR, Lewis MG, Stiegler G, Harris D, VanCott TC, et al. (1999) Protection of Macaques against pathogenic simian/human immunodeficiency virus 89.6PD by passive transfer of neutralizing antibodies. J Virol 73: 40094018.

8. Burton DR, Hessell AJ, Keele BF, Klasse PJ, Ketas TA, et al. (2011) Limited or no protection by weakly or nonneutralizing antibodies against vaginal SHIV challenge of macaques compared with a strongly neutralizing antibody. Proc Natl Acad Sci U S A 108: 11181-11186.

9. Zhu Z, Qin HR, Chen W, Zhao Q, Shen X, et al. (2011) Cross-reactive HIV-1neutralizing human monoclonal antibodies identified from a patient with $2 \mathrm{~F} 5$ like antibodies. J Virol 85: 11401-11408.

10. Whitney JB, Ruprecht RM (2004) Live attenuated HIV vaccines: pitfalls and prospects. Curr Opin Infect Dis 17: 17-26.

11. Hofmann-Lehmann R, Vlasak J, Williams AL, Chenine AL, McClure HM, et al. (2003) Live attenuated, nef-deleted SIV is pathogenic in most adult macaques after prolonged observation. AIDS 17: 157-166.

12. Johnston MI, Fauci AS (2007) An HIV vaccine--evolving concepts. N Engl J Med 356: 2073-2081.

13. Mascola JR, Snyder SW, Weislow OS, Belay SM, Belshe RB, et al. (1996) Immunization with envelope subunit vaccine products elicits neutralizing antibodies against laboratory-adapted but not primary isolates of human immunodeficiency virus type 1. The National Institute of Allergy and Infectious Diseases AIDS Vaccine Evaluation Group. J Infect Dis 173: 340-348.

14. VanCott TC, Bethke FR, Burke DS, Redfield RR, Birx DL (1995) Lack of induction of antibodies specific for conserved, discontinuous epitopes of HIV-1 envelope glycoprotein by candidate AIDS vaccines. J Immunol 155: 4100-4110.
15. (2003) VaxGen vaccine trial fails the test but may offer insights AIDS Alert 18: $41,43-45$

16. (2003) AIDS groups applaud VaxGen despite vaccine trial results AIDS Policy Law 18: 5.

17. Billich A (2004) AIDSVAX VaxGen. Curr Opin Investig Drugs 5: 214-221.

18. Haynes BF, Liao HX, Tomaras GD (2010) Is developing an HIV-1 vaccine possible? Curr Opin HIV AIDS 5: 362-367.

19. Forsell MN, Schief WR, Wyatt RT (2009) Immunogenicity of HIV-1 envelope glycoprotein oligomers. Curr Opin HIV AIDS 4: 380-387.

20. Barnett SW, Srivastava IK, Kan E, Zhou F, Goodsell A, et al. (2008) Protection of macaques against vaginal SHIV challenge by systemic or mucosal and systemic vaccinations with HIV-envelope. AIDS 22: 339-348.

21. Yang X, Wyatt R, Sodroski J (2001) Improved elicitation of neutralizing antibodies against primary human immunodeficiency viruses by soluble stabilized envelope glycoprotein trimers. J Virol 75: 1165-1171.

22. Beddows S, Franti M, Dey AK, Kirschner M, lyer SP, et al. (2007) A comparative immunogenicity study in rabbits of disulfide-stabilized, proteolytically cleaved soluble trimeric human immunodeficiency virus type $1 \mathrm{gp} 140$, trimeric cleavagedefective gp140 and monomeric gp120. Virology 360: 329-340.

23. Harris A, Borgnia MJ, Shi D, Bartesaghi A, He H, Pejchal R, et al. (2011) Trimeric HIV-1 glycoprotein gp140 immunogens and native HIV-1 envelope glycoproteins display the same closed and open quaternary molecular architectures. Proc Natl Acad Sci U S A 108: 11440-11445.

24. Hammonds J, Chen X, Ding L, Fouts T, De Vico A, et al. (2003) Gp120 stability on HIV-1 virions and Gag-Env pseudovirions is enhanced by an uncleaved Gag core. Virology 314: 636-649.

25. Willey RL, Martin MA, Peden KW (1994) Increase in soluble CD4 binding to and CD4-induced dissociation of gp120 from virions cRrrelates with infectivity of human immunodeficiency virus type 1. J Virol 68: 1029-1039.

26. McKeating JA, McKnight A, Moore JP (1991) Differential loss of envelope glycoprotein gp120 from virions of human immunodeficiency virus type 1 isolates: effects on infectivity and neutralization. J Virol 65: 852-860.

27. Walker LM, Phogat SK, Chan-Hui PY, Wagner D, Phung P, et al. (2009) Broad and potent neutralizing antibodies from an African donor reveal a new HIV-1 vaccine target. Science 326: 285-289.

28. Bachmann MF, Zinkernagel RM (1996) The influence of virus structure on antibody responses and virus serotype formation. Immunol Today 17: 553-558.

29. Burton DR, Pyati J, Koduri R, Sharp SJ, Thornton GB, et al. (1994) Efficient neutralization of primary isolates of HIV-1 by a recombinant human monoclonal antibody. Science 266: 1024-1027.

30. Muster T, Guinea R, Trkola A, Purtscher M, Klima A, et al. (1994) Crossneutralizing activity against divergent human immunodeficiency virus type 1 isolates induced by the gp41 sequence ELDKWAS. J Virol 68: 4031-4034

31. Muster T, Steindl F, Purtscher M, Trkola A, Klima A, et al. (1993) A conserved neutralizing epitope on gp41 of human immunodeficiency virus type 1 . J Virol 67: 6642-6647.

32. Doria-Rose NA, Klein RM, Manion MM, O'Dell S, Phogat A, et al. (2009) Frequency and phenotype of human immunodeficiency virus envelope-specific B cells from patients with broadly cross-neutralizing antibodies. J Virol 83: 188199.

33. Sather DN, Armann J, Ching LK, Mavrantoni A, Sellhorn G, et al. (2009) Factors associated with the development of cross-reactive neutralizing antibodies during human immunodeficiency virus type 1 infection. J Virol 83: 757-769.

34. Simek MD, Rida W, Priddy FH, Pung P, Carrow E, et al. (2009) Human immunodeficiency virus type 1 elite neutralizers: individuals with broad and potent neutralizing activity identified by using a high-throughput neutralization assay together with an analytical selection algorithm. J Virol 83: 7337-7348.

35. Walker LM, Huber M, Doores KJ, Falkowska E, Pejchal R, et al. (2011) Broad neutralization coverage of HIV by multiple highly potent antibodies. Nature 477 : 466-470.

36. Wu X, Yang ZY, Li Y, Hogerkorp CM, Schief WR, et al. (2010) Rational design of envelope identifies broadly neutralizing human monoclonal antibodies to HIV-1. Science 329: 856-861. 
Citation: Kong L, Sattentau QJ (2012) Antigenicity and Immunogenicity in HIV-1 Antibody-Based Vaccine Design. JAIDS Clinic Res S8:003. doi:10.4172/21556113.S8-003

37. Scheid JF, Mouquet H, Ueberheide B, Diskin R, Klein F, et al. (2011) Sequence and structural convergence of broad and potent HIV antibodies that mimic CD4 binding. Science 333: 1633-1637.

38. Clapham PR, Lu S (2011) Vaccinology: precisely tuned antibodies nab HIV. Nature 477: 416-417.

39. Tomaras GD, Binley JM, Gray ES, Crooks ET, Osawa K, et al. (2011) Polyclonal $B$ cell responses to conserved neutralization epitopes in a subset of HIV-1. infected individuals. J Virol 85: 11502-11519.

40. Walker LM, Simek MD, Priddy F, Gach JS, Wagner D, et al. (2010) A limited number of antibody specificities mediate broad and potent serum neutralization in selected HIV-1 infected individuals. PLoS Pathog 6: e1001028.

41. Nabel GJ, Kwong PD, Mascola JR (2011) Progress in the rational design of an AIDS vaccine. Philos Trans R Soc Lond B Biol Sci 366: 2759-2765.

42. Walker LM, Burton DR (2010) Rational antibody-based HIV-1 vaccine design: current approaches and future directions. Curr Opin Immunol 22: 358-366.

43. Kwong PD, Mascola JR, Nabel GJ (2011) Rational Design of Vaccines to Elicit Broadly Neutralizing Antibodies to HIV-1. Cold Spring Harb Perspect Med 1: a007278.

44. Schief WR, Ban YE, Stamatatos L (2009) Challenges for structure-based HIV vaccine design. Curr Opin HIV AIDS. 4: 431-440.

45. Yewdell JW (2006) Confronting complexity: real-world immunodominance in antiviral CD8+ T cell responses. Immunity 25: 533-543.

46. Pinter A, Honnen WJ, He Y, Gorny MK, Zolla-Pazner S, et al. (2004) The V1/V2 domain of gp120 is a global regulator of the sensitivity of primary human immunodeficiency virus type 1 isolates to neutralization by antibodies commonly induced upon infection. J Virol 78: 5205-5215.

47. Starcich BR, Hahn BH, Shaw GM, McNeely PD, Modrow S, et al. (1986) Identification and characterization of conserved and variable regions in the envelope gene of HTLV-III/LAV, the retrovirus of AIDS. Cell 45: 637-648.

48. Wei X, Decker JM, Wang S, Hui H, Kappes JC, et al. (2003) Antibody neutralization and escape by HIV-1. Nature 422: 307-312.

49. Dacheux L, Moreau A, Ataman-Onal Y, Biron F, Verrier B, et al. (2004) Evolutionary dynamics of the glycan shield of the human immunodeficiency virus envelope during natural infection and implications for exposure of the 2G12 epitope. J Virol 78: 12625-12637.

50. Wyatt R, Kwong PD, Desjardins E, Sweet RW, Robinson J, et al. (1998) The antigenic structure of the HIV gp120 envelope glycoprotein. Nature 393: 705711.

51. Reitter JN, Means RE, Desrosiers RC (1998) A role for carbohydrates in immune evasion in AIDS. Nat Med 4: 679-684.

52. Kwong PD, Doyle ML, Casper DJ, Cicala C, Leavitt SA, et al. (2002) HIV-1 evades antibody-mediated neutralization through conformational masking of receptor-binding sites. Nature 420: 678-682.

53. Yuan W, Bazick J, Sodroski J (2006) Characterization of the multiple conformational States of free monomeric and trimeric human immunodeficiency virus envelope glycoproteins after fixation by cross-linker. J Virol 80: 6725-6737.

54. Moore PL, Crooks ET, Porter L, Zhu P, Cayanan CS, et al. (2006) Nature of nonfunctional envelope proteins on the surface of human immunodeficiency virus type 1. J Virol 80: 2515-2528.

55. Parren PW, Burton DR, Sattentau QJ (1997) HIV-1 antibody--debris or virion? Nat Med 3: 366-367.

56. Pantophlet R, Burton DR (2006) GP120: target for neutralizing HIV-1 antibodies. Annu Rev Immunol 24: 739-769.

57. Burton DR, Stanfield RL, Wilson IA (2005) Antibody vs. HIV in a clash of evolutionary titans. Proc Natl Acad Sci U S A 102: 14943-14948.

58. Karlsson Hedestam GB, Fouchier RA, Phogat S, Burton DR, Sodroski J, et al. (2008) The challenges of eliciting neutralizing antibodies to HIV-1 and to influenza virus. Nat Rev Microbiol 6: 143-155.

59. Burton DR (2010) Scaffolding to build a rational vaccine design strategy. Proc Natl Acad Sci U S A 107: 17859-17860.

60. Correia BE, Ban YE, Friend DJ, Ellingson K, Xu H, et al. (2011) Computational protein design using flexible backbone remodeling and resurfacing: case studies in structure-based antigen design. J Mol Biol 405: 284-297.
61. Huang CC, Tang M, Zhang MY, Majeed S, Montabana E, et al. (2005) Structure of a V3-containing HIV-1 gp120 core. Science 310: 1025-1028.

62. Rusche JR, Javaherian K, McDanal C, Petro J, Lynn DL, et al. (1988) Antibodies that inhibit fusion of human immunodeficiency virus-infected cells bind a 24-amino acid sequence of the viral envelope, gp120. Proc Natl Acad Sci U S A 85: 3198-3202.

63. Hartley O, Klasse PJ, Sattentau QJ, Moore JP (2005) V3: HIV's switch-hitter AIDS Res Hum Retroviruses 21: 171-189.

64. Keller PM, Arnold BA, Shaw AR, Tolman RL, Van Middlesworth F, et al. (1993) Identification of HIV vaccine candidate peptides by screening random phage epitope libraries. Virology 193: 709-716.

65. Zolla-Pazner S, Kong XP, Jiang X, Cardozo T, Nádas A, et al. (2011) Cross-clade HIV-1 neutralizing antibodies induced with V3-scaffold protein immunogens following priming with gp120 DNA. J Virol 85: 9887-9898.

66. Zolla-Pazner S (2004) Identifying epitopes of HIV-1 that induce protective antibodies. Nat Rev Immunol 4: 199-210.

67. Van Regenmortel MH (2012) Requirements for empirical immunogenicity trials rather than structure-based design, for developing an effective HIV vaccine. Arch Virol 157: 1-20.

68. Van Regenmortel MH (2011) Limitations to the structure-based design of HIV-1 vaccine immunogens. J Mol Recognit 24: 741-753.

69. Van Regenmortel MH (2009) What is a B-cell epitope? Methods Mol Biol 524 3-20.

70. Ofek G, Guenaga FJ, Schief WR, Skinner J, Baker D, et al. (2010) Elicitation of structure-specific antibodies by epitope scaffolds. Proc Natl Acad Sci U S A 107: $17880-17887$

71. Correia BE, Ban YE, Holmes MA, Xu H, Ellingson K, et al. (2010) Computationa design of epitope-scaffolds allows induction of antibodies specific for a poorly immunogenic HIV vaccine epitope. Structure 18: 1116-1126.

72. Van Regenmortel MH (2011) Two meanings of reverse vaccinology and the empirical nature of vaccine science. Vaccine 29: 7875.

73. Cardoso RM, Zwick MB, Stanfield RL, Kunert R, Binley JM, et al. (2005) Broadly neutralizing anti-HIV antibody $4 \mathrm{E} 10$ recognizes a helical conformation of a highly conserved fusion-associated motif in gp41. Immunity 22: 163-173.

74. Ofek G, Tang M, Sambor A, Katinger H, Mascola JR, et al. (2004) Structure and mechanistic analysis of the anti-human immunodeficiency virus type 1 antibody 2F5 in complex with its gp41 epitope. J Virol 78: 10724-10737.

75. Liang X, Munshi S, Shendure J, Mark G 3rd, Davies ME, et al. (1999) Epitope insertion into variable loops of HIV-1 gp120 as a potential means to improve immunogenicity of viral envelope protein. Vaccine 17: 2862-2872.

76. Zhang H, Huang Y, Fayad R, Spear GT, Qiao L (2004) Induction of mucosal and systemic neutralizing antibodies against human immunodeficiency virus type 1 (HIV-1) by oral immunization with bovine Papillomavirus-HIV-1 gp41 chimeric virus-like particles. J Virol 78: 8342-8348.

77. Kusov YY, Zamjatina NA, Poleschuk VF, Michailov MI, Morace G, et al. (2007) Immunogenicity of a chimeric hepatitis A virus (HAV) carrying the HIV gp41 epitope 2F5. Antiviral Res 73: 101-111.

78. Ho J, Uger RA, Zwick MB, Luscher MA, Barber BH, et al. (2005) Conformational constraints imposed on a pan-neutralizing HIV-1 antibody epitope result in increased antigenicity but not neutralizing response. Vaccine 23: 1559-1573.

79. Coeffier E, Clement JM, Cussac V, Khodaei-Boorane N, Jehanno M, et al (2000) Antigenicity and immunogenicity of the HIV-1 gp41 epitope ELDKWA inserted into permissive sites of the MalE protein. Vaccine 19: 684-693.

80. Luo M, Yuan F, Liu Y, Jiang S, Song X, et al. (2006) Induction of neutralizing antibody against human immunodeficiency virus type 1 (HIV-1) by immunization with gp41 membrane-proximal external region (MPER) fused with porcine endogenous retrovirus (PERV) p15E fragment. Vaccine 24: 435-442.

81. Arnold GF, Velasco PK, Holmes AK, Wrin T, Geisler SC, et al. (2009) Broad neutralization of human immunodeficiency virus type 1 (HIV-1) elicited from human rhinoviruses that display the HIV-1 gp41 ELDKWA epitope. J Virol 83 5087-5100.

82. Kim M, Sun ZY, Rand KD, Shi X, Song L, et al. (2011) Antibody mechanics on a membrane-bound HIV segment essential for GP41-targeted viral neutralization. Nat Struct Mol Biol 18: 1235-1243. 
Citation: Kong L, Sattentau QJ (2012) Antigenicity and Immunogenicity in HIV-1 Antibody-Based Vaccine Design. JAIDS Clinic Res S8:003. doi:10.4172/21556113.S8-003

83. Mouquet H, Nussenzweig MC (2011) Polyreactive antibodies in adaptive immune responses to viruses. Cell Mol Life Sci.

84. Liao HX, Chen X, Munshaw S, Zhang R, Marshall DJ, et al. (2011) Initial antibodies binding to HIV-1 gp41 in acutely infected subjects are polyreactive and highly mutated. J Exp Med 208: 2237-2249.

85. Verkoczy L, Kelsoe G, Moody MA, Haynes BF (2011) Role of immune mechanisms in induction of HIV-1 broadly neutralizing antibodies. Curr Opin Immunol 23: 383-390.

86. Kwong PD, Wyatt R, Robinson J, Sweet RW, Sodroski J, et al. (1998) Structure of an HIV gp120 envelope glycoprotein in complex with the CD4 receptor and a neutralizing human antibody. Nature 393: 648-659.

87. Zhou T, Xu L, Dey B, Hessell AJ, Van RD, et al. (2007) Structural definition of a conserved neutralization epitope on HIV-1 gp120. Nature 445: 732-737.

88. Zhou T, Georgiev I, Wu X, Yang ZY, Dai K, et al. (2010) Structural basis for broad and potent neutralization of HIV-1 by antibody VRC01. Science 329: 811817.

89. Zwick MB, Bonnycastle LL, Menendez A, Irving MB, Barbas CF 3rd, et al (2001) Identification and characterization of a peptide that specifically binds the human, broadly neutralizing anti-human immunodeficiency virus type 1 antibody b12. J Virol 75: 6692-6699.

90. Dorgham K, Dogan I, Bitton N, Parizot C, Cardona V, et al. (2005) Immunogenicity of HIV type 1 gp120 CD4 binding site phage mimotopes. AIDS Res Hum Retroviruses 21: 82-92.

91. Boots LJ, McKenna PM, Arnold BA, Keller PM, Gorny MK, et al. (1997) Antihuman immunodeficiency virus type 1 human monoclonal antibodies that bind discontinuous epitopes in the viral glycoproteins can identify mimotopes from recombinant phage peptide display libraries. AIDS Res Hum Retroviruses 13: 1549-1559.

92. Scala G, Chen X, Liu W, Telles JN, Cohen OJ, et al. (1999) Selection of HIVspecific immunogenic epitopes by screening random peptide libraries with HIV1-positive sera. J Immunol 162: 6155-6161.

93. Azoitei ML, Correia BE, Ban YE, Carrico C, Kalyuzhniy O, et al. (2011) Computation-guided backbone grafting of a discontinuous motif onto a protein scaffold. Science 334: 373-376.

94. Honnen WJ, Krachmarov C, Kayman SC, Gorny MK, Zolla-Pazner S, et al. (2007) Type-specific epitopes targeted by monoclonal antibodies with exceptionally potent neutralizing activities for selected strains of human immunodeficiency virus type 1 map to a common region of the $\mathrm{V} 2$ domain of gp120 and differ only at single positions from the clade B consensus sequence. J Virol 81: 1424-1432.

95. McLellan JS, Pancera M, Carrico C, Gorman J, Julien JP, et al. (2011) Structure of HIV-1 gp120 V1/V2 domain with broadly neutralizing antibody PG9. Nature 480: 336-343.

96. Sattentau QJ (2011) Vaccinology: A sweet cleft in HIV's armour. Nature 480: 324-325

97. Pejchal R, Doores KJ, Walker LM, Khayat R, Huang PS, et al. (2011) A potent and broad neutralizing antibody recognizes and penetrates the HIV glycan shield. Science 334: 1097-1103.

98. Doores KJ, Bonomelli C, Harvey DJ, Vasiljevic S, Dwek RA, et al. (2010) Envelope glycans of immunodeficiency virions are almost entirely oligomannose antigens. Proc Natl Acad Sci U S A 107: 13800-13805.

99. Sanders RW, Venturi M, Schiffner L, Kalyanaraman R, Katinger H, et al. (2002) The mannose-dependent epitope for neutralizing antibody $2 \mathrm{G} 12$ on human immunodeficiency virus type 1 glycoprotein gp120. J Virol 76: 7293-7305.

100. Scanlan CN, Pantophlet R, Wormald MR, Ollmann Saphire E, Stanfield R, et al. (2002) The broadly neutralizing anti-human immunodeficiency virus type 1 antibody 2G12 recognizes a cluster of alpha1-->2 mannose residues on the outer face of gp120. J Virol 76: 7306-7321.

101. Calarese DA, Scanlan CN, Zwick MB, Deechongkit S, Mimura Y, et al. (2003) Antibody domain exchange is an immunological solution to carbohydrate cluster recognition. Science 300: 2065-2071.

102. Scanlan CN, Offer J, Zitzmann N, Dwek RA (2007) Exploiting the defensive sugars of HIV-1 for drug and vaccine design. Nature 446: 1038-1045.

103. Doores KJ, Fulton Z, Hong V, Patel MK, Scanlan CN, et al. (2010) A nonself sugar mimic of the HIV glycan shield shows enhanced antigenicity. Proc Nat Acad Sci U S A 107: 17107-17112.

104. Astronomo RD, Lee HK, Scanlan CN, Pantophlet R, Huang CY, et al. (2008) A glycoconjugate antigen based on the recognition motif of a broadly neutralizing human immunodeficiency virus antibody, $2 \mathrm{G} 12$, is immunogenic but elicits antibodies unable to bind to the self glycans of gp120. J Virol 82: 6359-6368.

105.Dunlop DC, Bonomelli C, Mansab F, Vasiljevic S, Doores KJ, et al. (2010) Polysaccharide mimicry of the epitope of the broadly neutralizing anti-HIV antibody, $2 \mathrm{G} 12$, induces enhanced antibody responses to self oligomannose glycans. Glycobiology 20: 812-823.

106. Douek DC, Kwong PD, Nabel GJ (2006) The rational design of an AIDS vaccine. Cell 124: 677-681.

107.Van Regenmortel MH (2001) Antigenicity and immunogenicity of synthetic peptides. Biologicals 29: 209-213.

108. Sweredoski MJ, Baldi P (2009) COBEpro: a novel system for predicting continuous B-cell epitopes. Protein Eng Des Sel 22: 113-120.

109. Westhof E, Altschuh D, Moras D, Bloomer AC, Mondragon A, et al. (1984) Correlation between segmental mobility and the location of antigenic determinants in proteins. Nature 311: 123-126.

110. Saha S, Raghava GP (2007) Prediction methods for B-cell epitopes. Methods Mol Biol 409: 387-394.

111. Batista FD, Neuberger MS (1998) Affinity dependence of the B cell response to antigen: a threshold, a ceiling, and the importance of off-rate. Immunity 8 : 751-759.

112. Wu X, Zhou T, Zhu J, Zhang B, Georgiev I, et al. (2011) Focused evolution of HIV-1 neutralizing antibodies revealed by structures and deep sequencing. Science 333: 1593-1602.

113. Kastenmuller W, Gasteiger G, Gronau JH, Baier R, Ljapoci R, et al. (2007) Cross-competition of CD8+ T cells shapes the immunodominance hierarchy during boost vaccination. J Exp Med 204: 2187-2198.

114. Chen L, Kwon YD, Zhou T, Wu X, O'Dell S, et al. (2009) Structural basis of immune evasion at the site of CD4 attachment on HIV-1 gp120. Science 326 : 1123-1127.

115. Sattentau QJ, Moore JP (1995) Human immunodeficiency virus type 1 neutralization is determined by epitope exposure on the gp120 oligomer. J Exp Med 182: 185-196.

116. Parren PW, Mondor I, Naniche D, Ditzel HJ, Klasse PJ, et al. (1998) Neutralization of human immunodeficiency virus type 1 by antibody to gp120 is determined primarily by occupancy of sites on the virion irrespective of epitope specificity. J Virol 72: 3512-3519.

117. Fouts TR, Binley JM, Trkola A, Robinson JE, Moore JP (1997) Neutralization of the human immunodeficiency virus type 1 primary isolate JR-FL by human monoclonal antibodies correlates with antibody binding to the oligomeric form of the envelope glycoprotein complex. J Virol 71: 2779-2785.

118. Li Y, Svehla K, Mathy NL, Voss G, Mascola JR, et al. (2006) Characterization of antibody responses elicited by human immunodeficiency virus type 1 primary isolate trimeric and monomeric envelope glycoproteins in selected adjuvants. J Virol 80: 1414-1426.

119. Changela A, Wu X, Yang Y, Zhang B, Zhu J, et al. (2011) Crystal structure of human antibody 2909 reveals conserved features of quaternary structurespecific antibodies that potently neutralize HIV-1. J Virol 85: 2524-2535.

120.Pancera M, McLellan JS, Wu X, Zhu J, Changela A, et al. (2010) Crysta structure of PG16 and chimeric dissection with somatically related PG9: structure-function analysis of two quaternary-specific antibodies that effectively neutralize HIV-1. J Virol 84: 8098-8110.

121.Zhang CW, Chishti Y, Hussey RE, Reinherz EL (2001) Expression, purification, and characterization of recombinant HIV gp140. The gp41 ectodomain of HIV or simian immunodeficiency virus is sufficient to maintain the retroviral envelope glycoprotein as a trimer. J Biol Chem 276: 39577-39585.

122. Moore JP, McKeating JA, Weiss RA, Sattentau QJ (1990) Dissociation of gp120 from HIV-1 virions induced by soluble CD4. Science 250: 1139-1142.

123. Chen B, Zhou G, Kim M, Chishti Y, Hussey RE, et al. (2000) Expression, purification, and characterization of gp160e, the soluble, trimeric ectodomain of the simian immunodeficiency virus envelope glycoprotein, gp160. J Bio Chem 275: 34946-34953. 
Citation: Kong L, Sattentau QJ (2012)Antigenicity and Immunogenicity in HIV-1 Antibody-Based Vaccine Design. JAIDS Clinic Res S8:003. doi:10.4172/21556113.S8-003

124. Pancera M, Lebowitz J, Schon A, Zhu P, Freire E, et al. (2005) Soluble mimetics of human immunodeficiency virus type 1 viral spikes produced by replacement of the native trimerization domain with a heterologous trimerization motif: characterization and ligand binding analysis. J Virol 79: 9954-9969.

125. Du SX, Idiart RJ, Mariano EB, Chen H, Jiang P, et al. (2009) Effect of trimerization motifs on quaternary structure, antigenicity, and immunogenicity of a noncleavable HIV-1 gp140 envelope glycoprotein. Virology 395: 33-44.

126. Pancera M, Majeed S, Ban YE, Chen L, Huang CC, et al. (2010) Structure of HIV-1 gp120 with gp41-interactive region reveals layered envelope architecture and basis of conformational mobility. Proc Natl Acad Sci U S A 107: 1166-1171.

127. Liu J, Bartesaghi A, Borgnia MJ, Sapiro G, Subramaniam S (2008) Molecular architecture of native HIV-1 gp120 trimers. Nature 455: 109-113.

128. Barnett SW, Lu S, Srivastava I, Cherpelis S, Gettie A, et al. (2001) The ability of an oligomeric human immunodeficiency virus type 1 (HIV-1) envelope antigen to elicit neutralizing antibodies against primary HIV-1 isolates is improved following partial deletion of the second hypervariable region. J Virol 75: 55265540

129. Yang X, Tomov V, Kurteva S, Wang L, Ren X, et al. (2004) Characterization of the outer domain of the gp120 glycoprotein from human immunodeficiency virus type 1. J Virol 78: 12975-12986.

130. Bhattacharyya S, Rajan RE, Swarupa Y, Rathore U, Verma A, et al. (2010) Design of a non-glycosylated outer domain-derived HIV-1 gp120 immunogen that binds to CD4 and induces neutralizing antibodies. J Biol Chem 285: $27100-27110$.

131. Chen H, Xu X, Jones IM (2007) Immunogenicity of the outer domain of a HIV-1 clade C gp120. Retrovirology 4: 33.

132. Garrity RR, Rimmelzwaan G, Minassian A, Tsai WP, Lin G, et al. (1997) Refocusing neutralizing antibody response by targeted dampening of an immunodominant epitope. J Immunol 159: 279-289.

133. Pantophlet R, Wilson IA, Burton DR (2003) Hyperglycosylated mutants of human immunodeficiency virus (HIV) type 1 monomeric gp120 as novel antigens for HIV vaccine design. J Virol 77: 5889-5901.

134. Selvarajah S, Puffer BA, Lee FH, Zhu P, Li Y, et al. (2008) Focused dampening of antibody response to the immunodominant variable loops by engineered soluble gp140. AIDS Res Hum Retroviruses 24: 301-314.

135. Pantophlet R, Burton DR (2003) Immunofocusing: antigen engineering to promote the induction of HIV-neutralizing antibodies. Trends Mol Med 9: 468473.
136. Pantophlet R, Wilson IA, Burton DR (2004) Improved design of an antigen with enhanced specificity for the broadly HIV-neutralizing antibody b12. Protein Eng Des Sel 17: 749-758.

137. Pantophlet R, Ollmann Saphire E, Poignard P, Parren PW, Wilson IA, et al. (2003) Fine mapping of the interaction of neutralizing and nonneutralizing monoclonal antibodies with the CD4 binding site of human immunodeficiency virus type $1 \mathrm{gp} 120$. J Virol 77: 642-658.

138. Bosques CJ, Tschampel SM, Woods RJ, Imperiali B (2004) Effects of glycosylation on peptide conformation: a synergistic experimental and computational study. J Am Chem Soc 126: 8421-8425.

139. Rudd PM, Woods RJ, Wormald MR, Opdenakker G, Downing AK, et al. (1995) The effects of variable glycosylation on the functional activities of ribonuclease plasminogen and tissue plasminogen activator. Biochim Biophys Acta 1248: 1-10.

140. Wormald MR, Dwek RA (1999) Glycoproteins: glycan presentation and protein-fold stability. Structure 7: R155-160.

141. Petrescu AJ, Milac AL, Petrescu SM, Dwek RA, Wormald MR (2004) Statistical analysis of the protein environment of $\mathrm{N}$-glycosylation sites: implications for occupancy, structure, and folding. Glycobiology 14: 103-114.

142. Malenbaum SE, Yang D, Cavacini L, Posner M, Robinson J, et al. (2000) The $\mathrm{N}$-terminal $\mathrm{V} 3$ loop glycan modulates the interaction of clade $\mathrm{A}$ and $\mathrm{B}$ human immunodeficiency virus type 1 envelopes with CD4 and chemokine receptors. J Virol 74: 11008-11016.

143. Koch M, Pancera M, Kwong PD, Kolchinsky P, Grundner C, et al. (2003) Structure-based, targeted deglycosylation of HIV-1 gp120 and effects on neutralization sensitivity and antibody recognition. Virology 313: 387-400.

144. Chen B, Vogan EM, Gong H, Skehel JJ, Wiley DC, et al. (2005) Structure of an unliganded simian immunodeficiency virus gp120 core. Nature 433: 834-841.

145. Kong L, Sheppard NC, Stewart-Jones GB, Robson CL, Chen H, et al. (2010) Expression-system-dependent modulation of HIV-1 envelope glycoprotein antigenicity and immunogenicity. J Mol Biol 403: 131-147.

146. Binley JM, Ban YE, Crooks ET, Eggink D, Osawa K, et al. (2010) Role of complex carbohydrates in human immunodeficiency virus type 1 infection and resistance to antibody neutralization. J Virol 84: 5637-5655.

147. Beverley PC, Healey D, Broadhurst K, Sattentau QJ (1989) Limitations of the anti-idiotype strategy for an HIV vaccine. J Autoimmun 2: 243-249.

148. Davis SJ, Schockmel GA, Somoza C, Buck DW, Healey DG, et al. (1992 Antibody and HIV-1 gp120 recognition of CD4 undermines the concept of mimicry between antibodies and receptors. Nature 358: 76-79.

This article was originally published in a special issue, Vaccine research: HIV handled by Editor(s). Dr. Marc Van Regenmortel, University of Strasbourg, France 